\title{
Annex 3: Inventory of appraisal techniques
}

\author{
Nikolaos IOANNIDIs \\ Vrije Universiteit Brussel.E-mail: Nikolaos.Ioannidis@vub.be.
}

\subsection{Introduction}

There are multiple 'recipes' for a proper impact assessment process. The purpose of this Annex is to provide a reference point and a knowledge base for conducting the process of integrated impact assessment of border control technologies. The Annex provides an overview of the appraisal and evaluation techniques, categorised as follows:

1) appraisal techniques that are explicitly referred in the General Data Protection Regulation (GDPR) and hence legally required to be used in the process of data protection impact assessment (DPIA) in the EU;

2) supplementary appraisal techniques that are compatible with the GDPR as far as the processes of DPIA and integrated impact assessment is concerned; and

3) evaluation techniques that are stand-alone, borrowed from other areas of practice, and can be integrated within the process of impact assessment; these evaluation techniques employ one or more appraisal techniques.

Under the first category are the appraisal methods explicitly stipulated in the GDPR. For the process of DPIA, the assessors use the following appraisal techniques: (i) assessment of necessity and proportionality of the personal data processing operations in relation to the purposes of the technology and (ii) assessment of the risks to the rights and freedoms of data subjects. The second category comprises closely related appraisal methods, which could be used more broadly on different types of assessments, not exclusively for DPIA. For example, cost-benefit analysis belongs to this category and can be used to supplement risk assessment legally required by the GDPR. Finally, the third category comprises stand-alone evaluation techniques with a view of their possible integration, such as technology foresight and environmental impact assessment (EIA). 
Several appraisal or evaluation techniques can be combined in order to conduct a process of integrated impact assessment, depending on the benchmark under assessment and the context in which the impact assessment process is utilised. Using one technique does not usually exclude or render obsolete the others. On the contrary, such a combination is frequently considered as best practice. There clearly exist many appraisal and evaluation techniques, of various levels of quality and applicability. Their abundance is due to the need for tailored solutions, adapted to the specific context of assessment. Additionally, the fact that impact assessment is an adaptable 'living instrument' results in existence of numerous versions and adaptations of the final impact assessment process.

Due to the evolving character of the concept of impact assessment, this Annex cannot be considered exhaustive. Although it extends as far as bringing together the well-established EIA with the newly conceived and relatively unclear concept of artificial intelligence impact assessment, there is no 'silver bullet' for selecting and combining the appraisal techniques that will be best adapted for an integrated impact assessment process.

This Annex is structured as follows: under each appraisal or evaluation technique, a list follows with corresponding sources prominent in the field (either academic or from the area of policymaking) (Sections 2-4). For instance, for DPIA, numerous methods and templates have been developed; however it is impossible to list each and every one of them. The scope of this Annex does not extend to the matter of combining several appraisal and evaluation techniques, although the list of sources under each technique indicates its affinity with others. In addition, Section 5 is dedicated to attempts to develop techniques for ranking technologies as to their invasiveness into societal values.

\subsection{Appraisal techniques explicitly required by the General Data Protection Regulation}

\subsubsection{Assessment of necessity and proportionality}

\subsubsection{Overview}

The necessity and proportionality assessment refers first and foremost to the observance of the personal data protection principles. In particular, it is connected to the principle of purpose limitation. It first asks about the purpose of the data processing operation, whether 'the processing could not be reasonably fulfilled by other means' and whether the personal data would be 'collected for specified, explicit and legitimate purposes and not further processed' in a way that is inconsistent with those purposes. ${ }^{1}$

This assessment further pertains to the principle of lawfulness of processing, alongside the principles of data minimisation, accuracy and storage limitation, security of processing, and also data protection by design and by default. In other words, it asks whether the 
personal data would be 'processed lawfully, fairly and in a transparent manner', whether it would be 'adequate, relevant and limited to what is necessary in relation to the purposes', whether it would be 'accurate and, where necessary, kept up to date' or whether it would be stored for any longer than necessary. ${ }^{2}$

Often, the envisaged initiative under assessment may voluntarily be additionally examined against the entirety of human rights limitation criteria. In other words, while the entirety of the provisions of the GDPR, and especially the personal data protection principles, is meant to observe human rights limitation criteria, there might be instances that would give rise to the questioning of such an assumption. This scenario could happen in the provisions about a national exemption or derogation from the GDPR (Article 85). The five limitation criteria, following the Charter of Fundamental Rights, are:

- legality, i.e. if a basis for a data processing operation is provided for by law of a sufficient quality, e.g. clarity, accessibility, precision, foreseeability, conformity with the rule of law;

- the respect for the essence of a right, i.e. if the interference with a fundamental right does not make it impossible to exercise a right;

- legitimacy, i.e. if a processing operation serves a given general interest or protects the rights and freedoms of others;

- necessity, i.e. if a processing operation is necessary and if it genuinely meets legitimate objectives; and

- proportionality sensu stricto (e.g. balancing), e.g. if the least intrusive option has been chosen.

\subsubsection{Assessment techniques}

Article 29 Data Protection Working Party

- Article 29 Data Protection Working Party, Guidelines on Data Protection Impact Assessment (DPIA) and determining whether processing is "likely to result in a high risk" for the purposes of Regulation 2016/679 (Brussels: 2017), https://www.cnil.fr/sites/default/files/atoms/files/20171013_wp248_ rev01_enpdf_4.pdf.

European Data Protection Supervisor (EDPS)

- European Data Protection Supervisor [EDPS], Accountability on the ground. Part II: Data Protection Impact Assessments \& Prior Consultation (Brussels: 2018), https://edps.europa.eu/sites/edp/files/ publication/18-02-06_accountability_on_the_ground_part_2_en.pdf.

- EDPS, Assessing the necessity of measures that limit the fundamental right to the protection of personal data: A Toolkit (Brussels: 2017), https://edps.europa.eu/sites/edp/files/publication/17-04-11_ necessity_toolkit_en_0.pdf.

- EDPS, Guidelines on assessing the proportionality of measures that limit the fundamental rightsto privacy and to the protection of personal data (Brussels: 2019), https://edps.europa.eu/sites/edp/files/ publication/19-12-19_edps_proportionality_guidelines2_en.pdf. 
Commission Nationale de l'Informatique et des Libertés (CNIL)

- CNIL, Privacy Impact Assessment (PIA). Templates (Paris, 2018), https://www.cnil.fr/sites/default/ files/atoms/files/cnil-pia-2-en-templates.pdf.

- CNIL, Privacy Impact Assessment (PIA). Methodology (Paris, 2018), https://www.cnil.fr/sites/default/ files/atoms/files/cnil-pia-1-en-methodology.pdf.

\subsubsection{Assessment of a risk to the rights and freedoms of data subjects}

\subsubsection{Risk assessment: an overview}

Risk assessment is the overall process of risk identification, risk analysis and risk evaluation. In particular, the purpose of risk analysis is to comprehend the nature of risk and its characteristics, including the level of risk. Risk analysis involves a detailed consideration of uncertainties, risk sources, consequences, likelihoods, events, scenarios, controls, and their effectiveness.

Risk analysis can be undertaken with varying degrees of detail and complexity, depending on the purpose of the analysis, the availability and reliability of information, and the resources available. Analysis techniques can be qualitative, quantitative or a combination of these, depending on the circumstances and intended use.

Consequent to risk analysis is the evaluation of the risks. This step involves comparing the results of the risk analysis with the established risk criteria to determine where additional action is required.

\subsection{Qualitative risk analysis}

Qualitative risk analysis uses a scale of qualifying attributes to describe the magnitude of potential consequences (e.g. low, medium and high) and the likelihood that those consequences will occur. An advantage of qualitative analysis is its ease of understanding by all relevant personnel, while a disadvantage is the dependence on the subjective choice of the scale. These scales can be adapted or adjusted to suit the circumstances, and different descriptions can be used for different risks. Qualitative analysis should use factual information and data, where available, and can be used:

1. as an initial screening activity to identify risks that require more detailed analysis;

2. where this kind of analysis is appropriate for decisions;

3. where numerical data or resources are inadequate for a quantitative risk analysis.

\subsection{Quantitative risk analysis}

Quantitative risk analysis uses a scale with numerical values (rather than the descriptive scales used in qualitative risk analysis) for both consequences and likelihood. The quality of the analysis depends on the accuracy and completeness of the numerical values and the validity of the models used. 
Quantitative risk analysis, in most cases, uses historical incident data, providing the advantage that they can be related directly to the information security objectives and concerns of the organisation. A disadvantage of the quantitative approach can occur where factual, auditable data are not available, thus creating an illusion of worth and accuracy of the risk assessment. The way in which consequences and likelihood are expressed and the ways in which they are combined to provide a level of risk, will vary according to the type of risk and the purpose for which the risk assessment output is to be used. The uncertainty and variability of both consequences and likelihood should be considered in the analysis and communicated effectively.

\subsubsection{Risks to the rights and freedoms in data protection law: an overview}

The concept of risk assessment within the scope of data protection law is understood to refer to the risks to the rights and freedoms of data subjects. On the grounds of the GDPR, risk is understood as a negative consequence arising from processing operations, which may or may not occur in the future. Such a consequence, if materialised, would produce physical, material, or non-material damage to natural persons (largely, data subjects) and not solely to the controllers or processors. Such risk includes, for example, discrimination, identity theft or fraud, financial loss or damage to reputation, loss of confidentiality, unauthorised reversal of pseudonymisation, any significant economic or social disadvantage, loss of control over personal data, and processing of unauthorised sensitive data or data from vulnerable natural persons, in particular children.

The classic method for assessing risk typically combines two measurements, namely its likelihood (or probability) and its severity. Risk can be assessed qualitatively, quantitatively or through a combination of these. ${ }^{3}$ There are aspects of personal data protection that fit into the former (i.e. risk to rights and freedoms) and the latter (e.g. data security).

Quantitative risk assessment measures the probability of occurrence of a risk, and combines this with its level of severity. Probability is expressed on a scale ranging from 0 to 1. In turn, qualitative risk assessment instead uses levels of likelihood (e.g. a four-partite descriptive scale of negligible, low, medium and high) to be combined with its severity. Eventually, severity of a risk indicates a magnitude of damage should a risk materialise. It can be equally expressed on a 4-partite descriptive scale. Both scales - likelihood and severity - are pre-defined and justified. 


\subsubsection{Assessment techniques}

International Organization for Standardization (ISO)

- ISO 31000:2018 Risk management - Guidelines, https://www.iso.org/standard/65694.html.

- ISO 27005:2018 Information technology - Security techniques - Information security risk management, https://www.iso.org/standard/75281.html.

- ISO 22301:2019 Security and resilience - Business continuity management systems - Requirements, https://www.iso.org/standard/75106.html.

\subsection{Supplementary appraisal techniques compatible with the General Data Protection Regulation}

\subsubsection{Scenario analysis (planning)}

\subsubsection{Overview}

Scenario analysis is conducted with the aim of analysing the impacts of possible future events on the system performance by taking into account several alternative outcomes, i.e. scenarios, and presenting different options for future development paths, resulting in varying outcomes and corresponding implications.

It is the process of forecasting the expected value of a performance indicator, given a time period, occurrence of different situations, and related changes in the values of system parameters under an uncertain environment. Scenario analysis can be used to estimate the behaviour of the system in response to an unexpected event, and may be utilised to explore the changes in system performance, in a theoretical best-case (optimistic) or worst-case (pessimistic) scenario.

Key steps in scenario analysis are: a) identification of the scenario field, b) identification of key factors, c) analysis of key factors, d) scenario generation, and e) scenario transfer. 


\subsubsection{Assessment techniques}

- Celeste Amorim Varuma and Carla Meloa, "Directions in Scenario Planning Literature - A Review of the Past Decades," Futures 42, no. 4 (2010): 355-69, https://doi.org/10.1016/j.futures.2009.11.021.

- Hannah Kosow and Robert Gaßner, Methods of Future and Scenario Analysis. Overview, Assessment, and Selection Criteria (2008), https://www.econstor.eu/bitstream/10419/199164/1/die-study-39.pdf.

- M.S. Reed, J. Kenter, A. Bonn, K. Broad, T.P. Burt, I.R. Fazey, E.D.G. Fraser, K. Hubacek, D. Nainggolan, C.H. Quinn, L.C. Stringer, F. Ravera, "Participatory scenario development for environmental management: A methodological framework illustrated with experience from the UK uplands," Journal of Environmental Management 128 (2013): 345-362, https://doi.org/10.1016/j. jenvman.2013.05.016.

- Philip Notten, Scenario Development: A Typology of Approaches, Think Scenarios, Rethink Education (2006), https:/www.oecd.org/site/schoolingfortomorrowknowledgebase/futuresthinking/scenarios/ scenariodevelopmentatypologyofapproaches.htm.

- Yousra Tourki, Jeffrey Keisler, and Igor Linkov, I., "Scenario analysis: a review of methods and applications for engineering and environmental systems", Environment Systems \& Decisions 33 (2013): 3-20, https://doi.org/10.1007/s10669-013-9437-6.

\subsubsection{Technology foresight}

\subsubsection{Overview}

Foresight is a systematic, participatory, future-intelligence-gathering, and medium-tolong-term vision-building process aimed at present-day decisions and mobilising joint actions.

Research foresight is "the process involved in systematically attempting to look into the longer-term future of science, technology, the economy and society with the aim of identifying the areas of strategic research and the emerging generic technologies likely to yield the greatest economic and social benefits.

Technology foresight is a systematic means of assessing those scientific and technological developments, which could have a strong impact on industrial competitiveness, wealth creation and quality of life.

Future-oriented technology analysis methods include, among others: creativity approaches, monitoring and intelligence, descriptive methods, matrices, statistical and trend analyses, road mapping, economic analyses, modelling and simulation. ${ }^{4}$ 


\subsubsection{Assessment techniques}

- Cinzia Battistella and Alberto F. De Toni, "A methodology of technological foresight: A proposal and field study," Technological Forecasting and Social Change 78, no. 6 (2011): 1029-1048, https://doi. org/10.1016/j.techfore.2011.01.006.

- M. Hussain, E. Tapinos, and L. Knight, "Scenario-Driven Roadmapping for Technology Foresight," Technological Forecasting and Social Change 124 (2017): 160-77, https://doi.org/10.1016/j.techfore.2017.05.005.

- Alan L. Porter, “Technology foresight: types and methods," International Journal Foresight and Innovation Policy 6, no. 1/2/3 (2010): 36-45, https://www.foresightfordevelopment.org/sobipro/ download-file/46-590/54.

\subsubsection{Cost-benefit analysis}

\subsubsection{Overview}

Cost-benefit analysis (CBA) is a tool for the allocation of resources and the selection of economically efficient policies, monetising all involved costs and benefits. It asks the question of whether a single initiative or more "should be undertaken and, if investable funds are limited, which one, two or more among these specific projects that would otherwise qualify for admission should be selected". ${ }^{5}$ Put simply, it is "a mathematical tool used by decision-makers to determine if the perceived program benefits outweigh expected costs" ${ }^{6}$

CBA guides decision-making by making a reference predominantly to profitability, ${ }^{7}$ in this way promoting efficiency understood as effectiveness as the least waste of resources. In the context of human rights, even values, if these could be translated into monetary terms, they might be better protected, taking into account the costs that occur when rights are violated. This approach could provide decision-makers with a more accurate methodology when human rights are affected. Yet, a criticism of this approach is that it might be unsuitable in certain contexts, as placing a monetary value on human life and suffering is morally illegitimate. ${ }^{8}$ 


\subsubsection{Assessment techniques}

- Stephanie Riegg Cellini and James Edwin Kee, "Cost-Effectiveness and Cost-Benefit Analysis," in Handbook of Practical Program Evaluation, eds. Kathryn E. Newcomer, Harry P. Hatry, and Joseph S. Wholey (New Jersey: John Wiley \& Sons, 2015), https://doi.org/10.1002/9781119171386.ch24.

- Ezra J. Mishan and Euston Quah, Cost-Benefit Analysis (Taylor \& Francis, 2007).

- European Commission, Guide to Cost-Benefit Analysis of Investment Projects, Economic appraisal tool for Cohesion Policy 2014-2020 (2014), https://ec.europa.eu/regional_policy/sources/docgener/ studies/pdf/cba_guide.pdf.

- Michael D. Makowsky and Richard E. Wagner, "From Scholarly Idea to Budgetary Institution: The Emergence of Cost-Benefit Analysis," Constitutional Political Economy 20, no. 1 (2009), https://doi. org/10.1007/s10602-008-9051-7.

- Pamela Misuraca, "The Effectiveness of a Costs and Benefits Analysis in Making Federal Government Decisions: A Literature Review," Igarss no. 1 (2014), https://doi.org/10.1007/s13398-014-0173-7.2.

- Robert H. Frank, "Why Is Cost-Benefit Analysis so Controversial?”, The Journal of Legal Studies 29, no. S2 (2000): 913, https://doi.org/10.1086/468099.

\subsubsection{Strengths, Weaknesses, Opportunities, Threats}

\subsubsection{Overview}

The analysis of strengths, weakness, opportunities and threats (SWOT) is a technique that provides the foundation for realisation of the desired alignment of organisational variables or issues. By listing favourable and unfavourable, internal and external issues in four quadrants of a grid, planners can better understand how strengths can be leveraged to realise new opportunities and how weaknesses can slow progress or magnify organisational threats, ${ }^{9}$ and hence act to remedy the latter.

However, other similar types of analyses exist, e.g. that of value, rarity, imitability and organisation (VRIO), which is designed to analyse the competitive implications of a firm's internal strengths and weaknesses, making it possibly useful at the micro-level within an organisation. ${ }^{10}$ At a more macro level, other analyses, e.g. PEST analysis (political, economic, socio-cultural and technological), with its derivatives (e.g. adding related societal concerns, such as legal or environmental ones), as well as the STEPE Framework (Social, Technical, Economic, Political, and Ecological) have been developed. ${ }^{11}$ 


\subsubsection{Assessment techniques}

- Hsu-Hsi Chang and Wen-Chih Huang "Application of a Quantification SWOT Analytical Method," Mathematical and Computer Modelling 43, no. 1-2 (2006): 158-69.

- Jay B. Barney, "Looking inside for Competitive Advantage”, Academy of Management Executive 9, no. 4 (1995): 49-61.

- John V. Richardson, "A Brief Intellectual History of the STEPE Model or Framework (i.e., the Social, Technical, Economic, Political, and Ecological)" (Los Angeles: 2016).

- Marilyn M. Helms and Judy Nixon, “Exploring SWOT Analysis - Where Are We Now?, Journal of Strategy and Management 3, no. 3: 215-16, https://doi.org/10.1108/17554251011064837.

- A. Paschalidou, M. Tsatiris, K. Kitikidou, C. Papadopoulou, "Methods (SWOT Analysis)," in Using Energy Crops for Biofuels or Food: The Choice. Green Energy and Technology (Springer, 2018), https:// doi.org/10.1007/978-3-319-63943-7_6.

\subsection{Standalone evaluation techniques}

\subsubsection{Environmental impact assessment}

\subsubsection{Overview}

Environmental Impact Assessment (EIA) is the process of identification, description and assessment of the direct and indirect effects of a project on: human beings, fauna and flora; soil, water, air, climate and the landscape; the interaction of these factors; and on material assets and cultural heritage. ${ }^{12}$

It is used as a tool to identify the environmental, social, and economic impacts of a project prior to decision-making. It aims to predict environmental impacts at an early stage in project planning and design, find ways and means to reduce adverse impacts, shape projects to suit the local environment, and present the predictions and options available to decision-makers. Through use of an EIA, both environmental and economic benefits can be achieved, such as reduced cost and time of project implementation and design, avoidance of treatment/clean-up costs and a better understanding of the impacts of laws and regulations.

The assessment consists of consecutive steps, namely scoping and screening of key issues, identification of impacts and analysis of their significance, impact mitigation, and monitoring and review. Public participation is highly encouraged..$^{13}$ 


\subsubsection{Assessment techniques}

- National Environmental Policy Act (NEPA) [United States]

- Council on Environmental Quality, Regulations for Implementing the Procedural Provisions of the National Environmental Policy Act, Washington 2005, https://ceq.doe.gov/laws-regulations/ regulations.html.

- Council on Environmental Quality, Collaboration in NEPA. A Handbook for NEPA Practitioners, Washington 2005, https://www.energy.gov/sites/prod/files/CEQ_Collaboration_in_ NEPA_10-2007.pdf.

- A. Lantieri, Z. Lukacova, J. McGuinn, and A. McNeill, Environmental Impact Assessment of Projects. Guidance on the preparation of the Environmental Impact Assessment Report (Brussels: 2007), https:// ec.europa.eu/environment/eia/pdf/EIA_guidance_EIA_report_final.pdf.

- Bram F. Noble, Bram F. Introduction to Environmental Impact Assessment. A Guide to Principles and Practice (Toronto: Oxford University Press, 2015).

- Randall J., Jowett E. Environmental impact assessment tools and techniques, World Wildlife Fund, Inc. and American National Red Cross (2010), https://www.sheltercluster.org/resources/documents/ grrt-3-environmental-impact-assessment-tools-and-techniques.

- SISSON project, Final environmental impact assessment (EIA) report, Chapter 5, Methods (2015), https://iaac-aeic.gc.ca/050/documents_staticpost/63169/93967/Sisson_EIA_July2013_Section_5-0_ EIA_Methods.pdf.

- UNESCO, Environmental Assessment Method, http://www.unesco.org/new/fileadmin/MULTIMEDIA/ HQ/CLT/pdf/ucha_Environmental_Assessment_Method_Southampton.pdf.

\subsubsection{Regulatory impact assessment}

\subsubsection{Overview}

A regulatory impact assessment (or analysis) (RIA) is a systemic approach to critically identify, assess and evaluate the positive and negative effects of proposed and existing regulations and non-regulatory alternatives. The process of RIA, for example, serves as a tool for the European Commission to estimate the economic, social, and environmental impacts of legislative proposals, non-legislative initiatives (e.g. financial programs) or implementing and delegating acts. It promotes informed decision-making and contributes to better regulation, but does not substitute policy-making per se.

The purpose of RIA is at least twofold: on the one hand, for policy-makers to support their reasoning as to why a policy option is preferable in terms of necessity, subsidiarity, proportionality, and objectives pursued compared to other options, and, on the other, for stakeholders (or the general public) to be able to provide feedback during the inception of the legislative process. 


\subsubsection{Assessment techniques}

- OECD, "Regulatory Impact Analysis: A Tool for Policy Coherence," in Regulatory Impact Analysis: A Tool for Policy Coherence (Paris: OECD Publishing, 2009), https://doi.org/10.1787/97892640671101-en.

- OECD, "Best Practice Principles for Regulatory Impact Analysis," in Regulatory Impact Assessment (2020), https://www.oecd-ilibrary.org/sites/663f08d9-en/index.html?itemId=/content/component/663f08d9-en.

- European Commission, “Guidelines on impact assessment," in Better regulation guidelines (2017), https://ec.europa.eu/info/sites/info/files/better-regulation-guidelines-impact-assessment.pdf.

- World Bank Group, Global Indicators of Regulatory Governance: Worldwide Practices of Regulatory Impact Assessments (2018), http://documents1.worldbank.org/curated/en/905611520284525814/ pdf/Global-Indicators-of-Regulatory-Governance-Worldwide-Practices-of-Regulatory-ImpactAssessments.pdf.

- Colin Kirkpatrick and David Parker “Regulatory Impact Assessment: An Overview," in Regulatory Impact Assessment: Towards Better Regulation? (Cheltenham: Edward Elgar Publishing, 2007), https://doi.org/10.4337/9781847208774.00007.

\subsubsection{Strategic niche management}

\subsubsection{Overview}

Strategic niche management is a tool supporting the "societal introduction of radical sustainable innovations". ${ }^{14}$ In other words, it is a technique designed to "facilitate the introduction and diffusion of new sustainable technologies through societal experiments. Its ultimate aim is to contribute to a broad shift to more sustainable economic development, through an integral combination of technological progress and system-wide social-institutional transformation". ${ }^{16}$

\subsubsection{Assessment techniques}

- Marjolein C.J. Caniëls and Henny A. Romijn, "Strategic Niche Management: Towards a Policy Tool for Sustainable Development," Technology Analysis \& Strategic Management 20, no. 2 (2008): 245-66, https://doi.org/10.1080/09537320701711264.

- R. Mourik and Rob Raven, A Practioner's View on Strategic Niche Management Towards a Future Research Outline (Energy research Centre of the Netherlands, 2006), https://publicaties.ecn.nl/ PdfFetch.aspx?nr=ECN-E--06-039. 


\subsubsection{Privacy impact assessment}

\subsubsection{Overview}

Privacy impact assessment (PIA) is the 'process for assessing the impacts on the fundamental right to privacy of a project, policy, program, service, product or other initiative and, in consultation with stakeholders, for taking remedial actions as necessary in order to avoid or minimise the negative impacts. ${ }^{17}$ It usually complements the DPIA process, compensating for the gaps identified where personal data are not processed, but the privacy of individuals is interfered with by a particular technology. ${ }^{18}$

Before the GDPR, and hence before the legal requirement to conduct, in detail, the DPIA process, PIA was the only type of assessment pertaining to processing personal data, while its scope would extent to all kinds of processing operations and technical and organisational measures. For instance, the scope of a PIA included the description of how personal data flowed within a project, analysing the possible impacts on individuals' privacy, identifying and recommending options for avoiding, minimising, or mitigating negative privacy impacts, building privacy considerations into the design of a project, etc. All these steps are nowadays embedded in the DPIA process, which lists in detail all the obligations of the data controller, while the PIA process is employed as a tool for assessing the impacts on the fundamental right to privacy.

\subsubsection{Assessment techniques}

- CNIL, Privacy Impact Assessment (PIA). Templates (Paris: 2018), https://www.cnil.fr/sites/default/ files/atoms/files/cnil-pia-2-en-templates.pdf.

- CNIL, Privacy Impact Assessment (PIA). Methodology (Paris: 2018), https://www.cnil.fr/sites/default/ files/atoms/files/cnil-pia-1-en-methodology.pdf.

- EL. Makri, Z. Georgiopoulou, and C. Lambrinoudakis, "A Proposed Privacy Impact Assessment Method Using Metrics Based on Organizational Characteristics," in Computer Security. CyberICPS 2019, SECPRE 2019, SPOSE 2019, ADIoT 2019. Lecture Notes in Computer Science, vol 11980, eds. S. Katsikas et al., (Springer, 2020), https://doi.org/10.1007/978-3-030-42048-2_9.

- Marie Caroline Oetzel and Sarah Spiekermann, "A systematic methodology for privacy impact assessments: a design science approach," European Journal of Information Systems 23, no. 2 (2014): 126-150, https://doi.org/10.1057/ejis.2013.18.

- Office of the Privacy Commissioner of Canada's, Guide to the Privacy Impact Assessment Process (2020), https://www.priv.gc.ca/en/privacy-topics/privacy-impact-assessments/gd_exp_202003/. 
- Konstantina Vemou and Maria Karyda, "An evaluation framework for privacy impact assessment methods," Conference: 12th Mediterranean Conference on Information Systems (MCIS2018) (2018), https://www.researchgate.net/publication/326723199_An_evaluation_framework_for_ privacy_impact_assessment_methods.

- David Wright and Paul Hert, "Introduction to Privacy Impact Assessment," in Privacy Impact Assessment (Dordrecht: Springer, 2012), 3-32, https://doi.org/10.1007/978-94-007-2543-0.

\subsubsection{Health impact assessment}

\subsubsection{Overview}

A health impact assessment (HIA), or, increasingly frequently, health technology assessment, is a 'systematic study of the consequences of the (introductory or continued) use of a technology in a particular context.' Health impact assessment owes its emergence to gaps in existing mechanisms for the promotion of health in institutional decision-making. ${ }^{19} \mathrm{~A}$ health impact assessment seeks to improve the quality of policy decisions by evaluating any positive or negative health impacts and making recommendations to maximise those deemed positive and mitigate those deemed negative. When properly utilised, health impact assessments recommend options for alternative decisions and mitigation strategies, with the aim of ensuring that any decisions made will protect and promote the population's health.

\subsubsection{Assessment techniques}

- Björn Hofmann, “On Value-Judgements and Ethics in Health Technology Assessment," Poiesis \& Praxis 3, no. 4 (2005): 278, https://doi.org/10.1007/s10202-005-0073-1.

- Jennifer S. Mindell, Anna Boltong, and Ian Forde, "A Review of Health Impact Assessment Frameworks," Public Health 122, no. 11 (2008): 1177-87, https://doi.org/10.1016/j.puhe.2008.03.014.

- World Health Organization. "WHO | Impact Assessment - Directory of References/Resources" (2010), http://www.who.int/heli/impacts/impactdirectory/en/index1.html.

- David Banta, Finn Børlum Kristensen, and Egon Jonsson, "A History of Health Technology Assessment at the European Level," International Journal of Technology Assessment in Health Care 25, no. 1 (2009): 68-73. https://doi.org/10.1017/S0266462309090448. 


\subsubsection{Ethics impact assessment}

\subsubsection{Overview}

An ethics impact assessment (eIA) is a process during which an organisation, together with stakeholders, considers the ethical issues or impacts posed by a new project, technology, service, program, piece of legislation, or other initiative, in order to identify risks and solutions.

The steps for conducting an ethics impact assessment could be: a) a decision on which methods should be used, b) a contingency analysis to evaluate the likelihood of ethical impacts, c) assessment of the relative importance of ethical impacts, including identification of potential or actual value conflicts, and e) clarification of the ethical impacts and the related ethical values/principles and formulation of workable conceptualisations. ${ }^{20}$

In addition, Reijers et al. has recently identified, through a systematic literature review, thirty-five different methods to "practice ethics in research and innovation" and arranged them into three groups: "(1) ex ante methods, dealing with emerging technologies, (2) intra methods, dealing with technology design, and (3) ex post methods, dealing with ethical analysis of existing technologies". ${ }^{21}$

Amongst these, the following are worthy of special mention:

- Value-Sensitive Design. Since the revelation that ethical values can be embedded into the process of design of, for example, a technology, ${ }^{22}$ many methods to do so have surfaced. One of them is the Value-Sensitive Design, which is a method of "design of a future system in which values of ethical importance are systematically explored throughout the design process to be included in the technical content of the system". ${ }^{23}$

- Care-Centred Value-Sensitive Design. A variant thereof, applicable to products and services for medical care, it "provides both an outline of the components demanding ethical attention as well as a step-by-step manner in which such considerations may proceed throughout the design process of a robot: beginning from the moment of idea generation and throughout the design of various prototypes". ${ }^{24}$

- Responsible Research and Innovation. This is a "transparent, interactive process by which societal actors and innovators become mutually responsive to each other with a view on the (ethical) acceptability, sustainability and societal desirability of the innovation process and its marketable products (in order to allow a proper embedding of scientific and technological advances in our society)"25. This concept is built on "six distinct dimensions termed as follows: engagement, gender equality, science education, ethics, open access and governance". ${ }^{26}$ Since its inception, the concept of Responsible Research and Innovation has become an underlying concept for all European Union funding for research and innovation. ${ }^{27}$ 


\subsubsection{Assessment techniques}

- Aimee van Wynsberghe, “A Method for Integrating Ethics into the Design of Robots," Industrial Robot: An International Journal 40, no. 5 (2013): 438, https://doi.org/10.1108/IR-12-2012-451.

- Asle H. Kiran, Nelly Oudshoorn, and Peter-Paul Verbeek, "Beyond Checklists: Toward an EthicalConstructive Technology Assessment," Journal of Responsible Innovation 2, no. 1 (2015): 5-19, https://doi.org/10.1080/23299460.2014.992769.

- Batya Friedman, Peter Kahn, and Alan Borning, Value Sensitive Design: Theory and Methods (University of Washington Technical, 2002), https://faculty.washington.edu/pkahn/articles/vsd-theorymethods-tr.pdf.

- Elin Palm and Sven Ove Hansson, “The Case for Ethical Technology Assessment (ETA)," Technological Forecasting and Social Change 73, no. 5 (2006), https://doi.org/10.1016/j.techfore.2005.06.002.

- Gill Ringland, “The Role of Scenarios in Strategic Foresight," Technological Forecasting and Social Change 77, no. 9 (2010), https://doi.org/10.1016/j.techfore.2010.06.010.

- High-Level Expert Group on Artificial Intelligence, The Assessment List for Trustworthy Artificial Intelligence (2020), https://ec.europa.eu/newsroom/dae/document.cfm?doc_id=60419.

- Tsjalling Swierstra and Arie Rip, "Nano-Ethics as NEST-Ethics: Patterns of Moral Argumentation about New and Emerging Science and Technology," NanoEthics 1, no. 1 (2007), https://doi. org/10.1007/s11569-007-0005-8.

- Wessel Reijers et. al, A Common Framework for Ethical Impact Assessment', Stakeholders Acting Together on the Ethical Impact Assessment of Research and Innovation (SATORI Project, 2016), https:// satoriproject.eu/media/D4.1_Annex_1_EIA_Proposal.pdf.

\subsubsection{Human rights impact assessment}

\subsubsection{Overview}

A human rights impact assessment (HRIA) can be defined as a continuous process for identifying, comprehending, evaluating and addressing the adverse effects emerging from a business project or from activities on the enjoyment of human rights enjoyment by impacted rights-holders, such as workers and community members. It is a relatively new field of impact assessment, compared to the environmental impact assessment or the social impact assessment. 


\subsubsection{Assessment techniques}

- Business for Social Responsibility, Conducting an Effective Human Rights Impact Assessment Guidelines, Steps, and Examples (2013), http://www.bsr.org/reports/BSR_Human_Rights_Impact_Assessments.pdf.

- James Harrison, "Measuring Human Rights: Reflections on the Practice of Human Rights Impact Assessment and Lessons for the Future," Warwick School of Law Research Paper No. 2010/26 (2010), http://dx.doi.org/10.2139/ssrn.1706742.

- Nora Götzmann, Tulika Bansal, Elin Wrzoncki, Cathrine Poulsen-Hansen, Jacqueline Tedaldi, and Roya Høvsgaard, Human rights impact assessment guidance and toolbox (The Danish Institute for Human Rights, 2016), https://www.humanrights.dk/sites/humanrights.dk/files/media/dokumenter/ business/hria_toolbox/hria_guidance_and_toolbox_final_feb2016.pdf.

- Nordic Trust Fund and The World Bank, Study on Human Rights Impact Assessments: A Review of the Literature, Differences with other Forms of Assessments and Relevance for Development (2013) https://documents1.worldbank.org/curated/en/834611524474505865/pdf/125557-WP-PUBLICHRIA-Web.pdf.

- Alessandro Mantelero, "AI and Big Data: A Blueprint for a Human Rights, Social and Ethical Impact Assessment," Computer Law \& Security Review 34, no. 4 (2018): 754-772, https://ssrn.com/ abstract $=3225749$.

\subsubsection{Social impact assessment}

\subsubsection{Overview}

Social impact assessment (SIA) is the process of identifying and managing the social impacts of envisaged projects. It includes the processes of analysing, monitoring, and managing the intended and unintended social consequences, both positive and negative, of planned interventions (including, but not limited to, policies, programs, plans and projects) and any social change processes invoked by those interventions. It is used to predict and mitigate negative impacts and identify opportunities to enhance benefits for local communities and broader society.

The process of an SIA might be both quantitative (statistical) and qualitative (observation, interviews, case studies etc.). It begins with the identification of needs and social problems, participants, and beneficiaries. It continues with the description of action and the initial conditions. It then establishes methods of interaction with affected groups and gauges each alternative. Furthermore, it measures the direct impact of the project, as well as indirect and cumulative impacts. It concludes with recommendations and a plan to counter the impact of undesirable social effects. ${ }^{28}$ 


\subsubsection{Assessment techniques}

- Raluca Antonie, "Social Impact Assessment Models," Transylvanian Review of Administrative Sciences 29E (2010), https://rtsa.ro/tras/index.php/tras/article/view/39.

- Leon Hempel, Lars Ostermeier, Tobias Schaaf, and Dagny Vedder, "Towards a Social Impact Assessment of Security Technologies: A Bottom-up Approach," Science and Public Policy 40 (2013): 740-54, https://doi.org/10.1093/scipol/sct086.

- Henk Becker and Frank Vanclay, The International Handbook of Social Impact Assessment (Cheltenham: Edward Elgar, 2003), https://doi.org/10.4337/9781843768616.

- Frank Vanclay, Ana Maria Esteves, Ilse Aucamp, and Daniel M. Franks. Social Impact Assessment: Guidance for Assessing and Managing the Social Impacts of Projects (Fargo: International Association for Impact Assessment 2015), https://espace.library.uq.edu.au/view/UQ:355365.

\subsubsection{Technology assessment}

\subsubsection{Overview}

Technology assessment (TA) is defined as a class of policy studies that systematically examine the effects on society that may occur when a technology is introduced, extended or modified. It places an emphasis on those consequences that are unintended, indirect or delayed. ${ }^{29}$

Technology assessment follows the same pattern, with identification of the technology under assessment and affected stakeholders. It continues with an analysis of the precise functionality of the technology and the extent to which it serves its purpose, and finishes with appropriate documentation and a review.

Among the modes of understanding and performing a TA, four approaches are prominent: the classical TA (informing the political sphere about a technology), the participatory TA (enabling the interaction between politicians and society), the argumentative TA (informing about the core values driving science and technology), and the constructive TA (bridging the gap between society and science and technology). ${ }^{30}$ 


\subsubsection{Assessment techniques}

- Armin Grunwald, “Technology Assessment: Concepts and Methods," in Philosophy of Technology and Engineering Sciences, ed. Anthonie Meijers (Amsterdam: Elsevier, 2009), 1103-46, https://doi. org/10.1016/B978-0-444-51667-1.50044-6.

- Joseph F. Coates, "Some methods and techniques for comprehensive impact assessment," Technological Forecasting and Social Change 6 (1974): 341-57, https://doi.org/10.1016/0040-1625(74)90035-3.

- Rinie van Est, “The Rathenau Institute's approach to participatory Technology Assessment,” TA-Datenbank Nachrichten 9, no. 3 (2000): 13-20, https://research.tue.nl/en/publications/the-rathenau-institutes-approach-to-participatory-technology-asse.

- Jan Van Den Ende, Karel Mulder, Marjolijn Knot, Ellen Moors, Philip Vergragt, "Traditional and Modern Technology Assessment: Toward a Toolkit," Technological Forecasting and Social Change 58, no. 1-2 (1998): 5-21, https://doi.org/10.1016/S0040-1625(97)00052-8.

- Richard Sclove, Reinventing Technology Assessment: A 21st Century Model (Washington: Science and Technology Innovation Program, WoodrowWilson International Center for Scholars, 2010), https:// doi.org/10.13140/RG.2.1.3402.5364.

\subsubsection{Artificial intelligence impact assessment}

\subsubsection{Overview}

Algorithms are increasingly being adopted for the purpose of decision-making, at the expense of human agency. This is already visible in online advertising, social media, and welfare distribution, to name but a few spheres. Such algorithms work by means of data processing, profiling, and inference-drawing, supported by the utilisation of artificial intelligence (AI) and machine learning.

A tool for assessing the impact of artificial intelligence might be warranted in order to cover aspects that have not been taken into consideration by the DPIA. Both instruments are complementary, but not interchangeable, as the artificial intelligence impact assessment (AIIA) is a broader instrument, which focuses on all possible ethical and legal issues that can be associated with the deployment of AI, including the processing of personal data.

Policy developments in the area of AI conclude in the obligation to conduct a process of conformity assessment for high-risk AI systems, with a view to demonstrating their conformity with requirements, such as documentation, record keeping, human oversight, transparency, and provision of information to users. 


\subsubsection{Assessment techniques}

- ECP - Platform for the Information Society, Artificial Intelligence Impact Assessment (2018), https:// ecp.nl/wp-content/uploads/2019/01/Artificial-Intelligence-Impact-Assessment-English.pdf.

- Margot E. Kaminski and Gianclaudio Malgieri, "Algorithmic Impact Assessments under the GDPR: Producing Multi-layered Explanations," International Data Privacy Law (2020): ipaa020, https://doi. org/10.1093/idpl/ipaa020.

- Dillon Reisman, Jason Schultz, Kate Crawford, and Meredith Whittaker, Algorithmic impact assessments: A practical framework for public agency accountability (AI Now Institute, 2018), https:// ainowinstitute.org/aiareport2018.pdf.

\subsection{Technology ranking techniques}

\subsubsection{Overview}

With the increased use of quantification (metrification, numerification) and actuarial techniques for decision-making (e.g. probability theory, insurance, statistics) over the last century, a plethora of assessment techniques (e.g. SURVEILLE, ${ }^{31}$ DETECTER $^{32}$ and HECTOS $^{33}$ ) have been developed in order to rank the maleficence or, alternatively, beneficence of given technologies, including surveillance and border control technologies. By assigning a numerical grade or a ranking of intrusiveness (interference, invasiveness, etc.) or conformity with a given standard, these assessment techniques allow for an easy comparison of two or more such technologies with a view to making a decision as to their deployment. Such rankings have the benefit of increasing efficiency and eventually granting legitimisation to decision-making processes. Yet, despite their benefits, such ranking techniques are too simplistic and reductionist, assuming the commensurability of the technologies under analysis, and over-simplifying the complexities involved in decision-making.

\subsubsection{Literature}

- Siddharth Sareen, Andrea Saltelli, and Kjetil Rommetveit, "Ethics of quantification: illumination, obfuscation, and performative legitimation," Palgrave Communications 6, no. 1 (2020): 20, https:// doi.org/10.1057/s41599-020-0396-5.

- Andrea Saltelli, "Ethics of quantification or quantification of ethics?" Futures 116 (2020): 102509, https://doi.org/10.1016/j.futures.2019.102509.

- Zora, Kovacic, "Conceptualizing Numbers at the Science-Policy Interface," Science, Technology, \& Human Values 43, no. 6 (2018): 1039-65, https://doi.org/10.1177/0162243918770734. 


\section{Endnotes}

1. Dariusz Kloza et al., 'Towards a Method for Data Protection Impact Assessment: Making Sense of GDPR Requirements', d.pia.lab Policy Brief (Brussels: VUB, 2019), 1, https://doi. org/10.31228/osf.io/es8bm.

2. Ibid.

3. ISO/IEC 27000:2018, Information technology - Security techniques - Information security management systems - Overview and vocabulary, ISO 27000:2018, Geneva.

4. A.L. Porter (2010), “Technology foresight: types and methods," International Journal Foresight and Innovation Policy 6, No. 1/2/3 (2010): 36-45.

5. E. J. Mishan and Euston Quah, Cost-Benefit Analysis (London: Routledge, 2007), 4.

6. Michael D. Makowsky and Richard E. Wagner, "From Scholarly Idea to Budgetary Institution: The Emergence of Cost-Benefit Analysis," Constitutional Political Economy 20, no. 1 (2009): 62, https://doi.org/10.1007/s10602-008-9051-7; Pamela Misuraca, "The Effectiveness of a Costs and Benefits Analysis in Making Federal Government Decisions: A Literature Review," Igarss 2014, no. 1 (2014): 1, https://doi.org/10.1007/s13398-014-0173-7.2.

7. Mishan and Quah, Cost-Benefit Analysis.

8. Robert H. Frank, "Why Is Cost-Benefit Analysis so Controversial?," The Journal of Legal Studies 29, no. S2 (2000): 913-30, https://doi.org/10.1086/468099.

9. Marilyn M. Helms and Judy Nixon, "Exploring SWOT Analysis - Where Are We Now?," Journal of Strategy and Management 3, no. 3 (2010): 215-51, https://doi. org/10.1108/17554251011064837.

10. Jay B. Barney, 'Looking inside for Competitive Advantage', Academy of Management Executive 9, no. 4 (1995): 49-61.

11. John V. Richardson, "A Brief Intellectual History of the STEPE Model or Framework (i.e., the Social, Technical, Economic, Political, and Ecological)" (Los Angeles, 2016).

12. UNESCO, 'Environmental Assessment Method', http://www.unesco.org/new/fileadmin/MULTIMEDIA/HQ/CLT/pdf/ucha_Environmental_Assessment_Method_Southampton.pdf.

13. Ibid.

14. R. Mourik and Rob Raven, A Practioner's View on Strategic Niche Management Towards a

15. Future Research Outline (Energy research Centre of the Netherlands, 2006), https://publicaties.ecn.nl/PdfFetch.aspx?nr=ECN-E--06-039.

16. Marjolein C.J. Caniëls and Henny A Romijn, "Strategic Niche Management: Towards a Policy Tool for Sustainable Development," Technology Analysis \& Strategic Management 20, no. 2 (2008): 245-66, https://doi.org/10.1080/09537320701711264.

17. David Wright and Paul Hert, "Privacy Impact Assessment," in Privacy Impact Assessment (Dordrecht: Springer, 2012), 3-32, https://doi.org/10.1007/978-94-007-2543-0.

18. Paul De Hert, Dariusz Kloza, and David Wright, "Recommendations for a Privacy Impact Assessment Framework for the European Union" (Brussels - London, 2012), https://researchportal.vub.be/files/14231615/PIAF_D3_final.pdf.

19. Björn Hofmann, "On Value-Judgements and Ethics in Health Technology Assessment," Poiesis \& Praxis 3, no. 4 (2005): 277-95, https://doi.org/10.1007/s10202-005-0073-1.

20. Wessel Reijers et. al (2016), 'A Common Framework for Ethical Impact Assessment', Stakeholders Acting Together on the Ethical Impact Assessment of Research and Innovation - SATORI project https://satoriproject.eu/media/D4.1_Annex_1_EIA_Proposal.pdf.

21. Wessel Reijers et al., "Methods for Practising Ethics in Research and Innovation: A Literature Review, Critical Analysis and Recommendations," Science and Engineering Ethics 24, no. 5 (2018): 1437-81, https://doi.org/10.1007/s11948-017-9961-8. 
22. Helen Nissenbaum, "How Computer Systems Embody Values," Computer 34, no. 3 (2001): 117-19, https://doi.org/10.1109/2.910905.

23. Aimee van Wynsberghe, "Designing Robots with Care" (University of Twente, 2012), 10, https://doi.org/10.3990/1.9789036533911.

24. Aimee van Wynsberghe, "A Method for Integrating Ethics into the Design of Robots," Industrial Robot: An International Journal 40, no. 5 (2013): 433-40, https://doi.org/10.1108/ IR-12-2012-451.

25. René von Schomberg, ed., Towards Responsible Research and Innovation in the Information and Communication Technologies and Security Technologies Fields (Luxembourg: Publications Office of the European Union, 2011), 9.

26. Mirjam Burget, Emanuele Bardone, and Margus Pedaste, "Definitions and Conceptual Dimensions of Responsible Research and Innovation: A Literature Review," Science and Engineering Ethics 23, no. 1 (February 2017): 9, https://doi.org/10.1007/s11948-016-9782-1.

27. cf. Rome Declaration on Responsible Research and Innovation in Europe, 21 November 2014; https://ec.europa.eu/research/swafs/pdf/rome_declaration_RRI_final_21_November.pdf; Regulation (EU) No 1290/2013 of the European Parliament and of the Council of 11 December 2013 laying down the rules for participation and dissemination in "Horizon 2020 - the Framework Programme for Research and Innovation (2014-2020)" and repealing Regulation (EC) No 1906/2006, OJ L 347, 20.12.2013, pp. 81-103; Regulation (EU) No 1291/2013 of the European Parliament and of the Council of 11 December 2013 establishing Horizon 2020 - the Framework Programme for Research and Innovation (2014-2020) and repealing Decision No 1982/2006/EC, OJ L 347, 20.12.2013, pp. 104-173. cf. also https:// www.rri-tools.eu.

28. Raluca Antonie, "Social Impact Assessment Models," Transylvanian Review of Administrative Sciences 29E (2010), https://rtsa.ro/tras/index.php/tras/article/view/39.

29. Joseph F. Coates, “Technology Assessment - A Tool Kit,” Chemtech (1976): 372-383.

30. Rinie van Est, “The Rathenau Institute's approach to participatory Technology Assessment," TA-Datenbank Nachrichten 9, no. 3 (2000): 13-20, https://research.tue.nl/en/publications/ the-rathenau-institutes-approach-to-participatory-technology-asse.

31. Surveillance: Ethical Issues, Legal Limitations, and Efficiency, 2012-15, https://cordis.europa. $\mathrm{eu} / \mathrm{project} / \mathrm{id} / 284725$.

32. Detection Technologies, Terrorism, Ethics and Human Rights, 2008-12, https://cordis.europa. $\mathrm{eu} / \mathrm{project} / \mathrm{id} / 217862$.

33. Harmonized Evaluation, Certification and Testing of Security Products, 2014-18, https://cordis.europa.eu/project/id/606861, http://hectos-fp7.eu/. 